\title{
Squalomix: shark and ray genome sequencing to analyze their diversity and evolution
}

Shigehiro Kuraku ${ }^{1}$ and Squalomix Consortium Members ${ }^{1}$

${ }^{1}$ Affiliation not available

June 29, 2021

\section{Hosted file}

Squalomix-PositionPaper-forAuthorea.pdf available at https://authorea.com/users/386789/ articles/528239-squalomix-shark-and-ray-genome-sequencing-to-analyze-their-diversityand-evolution 